\title{
Identificação de Fungos Emboloradores em Madeira de Pinus spp. em Laboratório
}

\author{
Marilia Lazarotto ${ }^{1}$, Leonardo da Silva Oliveira ${ }^{2}$, Ricardo Harakava ${ }^{3}$, \\ Paula Zanatta ${ }^{4}$, Candida Renata Jacobsen de Farias ${ }^{5}$
}

${ }^{1}$ Departamento de Horticultura e Silvicultura, Universidade Federal do Rio Grande do Sul - UFRGS, Porto Alegre/RS, Brasil

${ }^{2}$ Centro de Engenharias - CENg, Universidade Federal de Pelotas - UFPel, Pelotas/RS, Brasil ${ }^{3}$ Instituto Biológico de São Paulo, São Paulo/SP, Brasil

${ }^{4}$ Programa de Pós-graduação em Ciência e Engenharia de Materiais, Universidade Federal de Pelotas - UFPel, Pelotas/RS, Brasil

${ }^{5}$ Faculdade de Agronomia Eliseu Maciel, Universidade Federal de Pelotas - UFPel, Pelotas/RS, Brasil

\section{RESUMO}

O objetivo deste estudo foi identificar, em nível de espécie, fungos emboloradores em madeira não tratada de Pinus spp. estocada em ambiente de laboratório, em Pelotas, Rio Grande do Sul. Para tanto, 10 amostras de madeira de pinus atacadas por fungos de bolor foram selecionadas para identificação das estruturas fúngicas por meio de identificação morfológica de esporos e, posteriormente, esses foram isolados e enviados para sequenciamento do fator de elongação 1-alpha (EF-1a), para sua identificação molecular. Foram obtidos cinco isolados do gênero Trichoderma e um isolado do gênero Fusarium. Esses foram identificados por meio de análise molecular como pertencentes às espécies T. atroviride e F. solani, respectivamente.

Palavras-chave: conífera, biologia molecular, biodeterioração da madeira.

\section{Identification of Mold Fungi in Pinus Wood Under Laboratory Conditions}

\begin{abstract}
The objective of this study was to identify the species of mold fungi in untreated wood of Pinus spp. stored at laboratory conditions in Pelotas, Rio Grande do Sul, Brazil. For this purpose, 10 Pinus spp. wood samples were randomly selected for fungal structures identification by morphological spores and subsequently, these were isolated and sent elongation factor 1-alpha (EF-1a) sequencing for molecular identification. Five isolates were obtained from the genus Trichoderma and one isolate of Fusarium. These were identified by molecular analysis as belonging to the species T. atroviride and F. solani, respectively.
\end{abstract}

Keywords: conifer, molecular biology, wood biodeterioration. 
A deterioração e a descoloração causadas por fungos são as principais formas de desvalorização na produção de madeira, com perdas de $15 \%$ a $25 \%$ do valor da árvore e de $10 \%$ a 15\% de produtos de madeira durante a estocagem e utilização (Kelley et al., 2002). Normalmente, os primeiros fungos que colonizam as árvores recém-cortadas são os manchadores e os emboloradores de madeira. Isso ocorre em razão da grande quantidade de substâncias de reserva, das quais esses organismos se nutrem, e à elevada umidade do material, o que propicia o seu desenvolvimento (Hanada et al., 2003). Segundo os autores citados, quando atacada por fungos emboloradores, a madeira apresentará, em sua superfície, áreas pulverulentas, de coloração variada, constituídas de massa de esporos.

De acordo com a Indústria Brasileira de Árvores (IBÁ, 2015), o gênero Pinus é o segundo mais cultivado no Rio Grande do Sul, ocupando aproximadamente 184.585 ha de área plantada. A madeira desse gênero caracteriza-se por apresentar baixa durabilidade natural, sendo necessária a aplicação de tratamento químico para aumento de sua vida útil. Entretanto, esses tratamentos apresentam algum grau de toxidez, tornando a madeira inadequada para certos usos. O material mais utilizado para embalagem de hortaliças, no Brasil, é a madeira, sendo a maior parte proveniente de áreas de reflorestamento com espécies de Pinus e, em menor escala, com Eucalyptus (Henz \& Cardoso, 2005).

Apesar da grande importância dos fungos emboloradores, especialmente com relação à utilização de madeira sem tratamento, poucos estudos se detêm a identificar esses agentes, quando comparados a estudos de identificação de agentes apodrecedores de madeira. Dessa forma, este estudo teve como objetivo identificar, em nível de espécie, fungos emboloradores na madeira não tratada de Pinus spp. estocada em laboratório, em Pelotas, Rio Grande do Sul.

A seleção de amostras e identificação visual dos fungos emboloradores de madeira foram realizadas no Laboratório de Biodegradação da Madeira, Centro de Engenharias (CEng), Universidade Federal de Pelotas (UFPel). Para tanto, 10 amostras de madeira de Pinus spp. com elevado teor de umidade, produzidas por serrarias do município de Pelotas, Rio Grande do Sul, e estocadas em laboratório por período superior a um ano, foram selecionadas aleatoriamente para visualização e identificação das estruturas fúngicas.
As amostras apresentavam as dimensões: $25,6 \mathrm{~mm}$ de espessura x $100 \mathrm{~mm}$ de largura x $150 \mathrm{~mm}$ de comprimento.

Para identificação visual foi realizada a preparação de lâminas semipermanentes com o corante azul de algodão e lactofenol. A descrição morfológica dos fungos foi comparada com as descrições na literatura especializada. Após a identificação, os fungos foram repicados para meio de cultivo extrato de malte ágar (Zauza et al., 2007) em câmara de fluxo laminar, purificados para o procedimento de sequenciamento no Instituto Biológico de São Paulo, estado de São Paulo, Brasil.

Cada isolado foi identificado com um código e a extração de ácido desoxirribonucleico (DNA) foi realizada do patógeno. As amostras de DNA genômico extraídas foram submetidas à Reação da Polimerase em Cadeia (PCR) para a amplificação da região fator de elongação 1-alpha com o par de primers EF1-T (ATGGGTAAGGARGACAAGAC) e EF1-1567R (ACHGTRCCRATACCACCRATCTT) (Rehner \& Buckley, 2005). O sequenciamento foi realizado em sequenciador Mega BACE 500 (Amersham). As sequências de nucleotídeos obtidas foram comparadas com as já existentes no banco de genoma GenBank para os gêneros identificados. A análise filogenética foi conduzida utilizando-se o método estatístico Neighbour-joining com base em 1.000 réplicas de bootstrap. As distâncias evolutivas foram calculadas usando-se o modelo Tamura-Nei.

Dentre os isolados coletados nas amostras de pinus foram identificados 5 de Trichoderma spp. e 1 de Fusarium sp. Esse último só teve a identidade revelada após análise molecular, pois não apresentava esporulação no momento da identificação morfológica. Como pode ser observado na Figura 1, todos os isolados de Trichoderma sp. foram identificados como pertencentes à espécie T. atroviride.

Fungos do gênero Trichoderma são organismos de vida livre, que se reproduzem assexuadamente, presentes com mais frequência em solos de regiões de clima temperado e tropical. Esses podem também colonizar madeira, onde a fase sexual teleomorfa (gênero Hypocrea) é frequentemente encontrada (Machado et al., 2012). Na madeira, dificilmente causam deterioração, porém, o alburno atacado por esses fungos pode exibir áreas de coloração variável, 


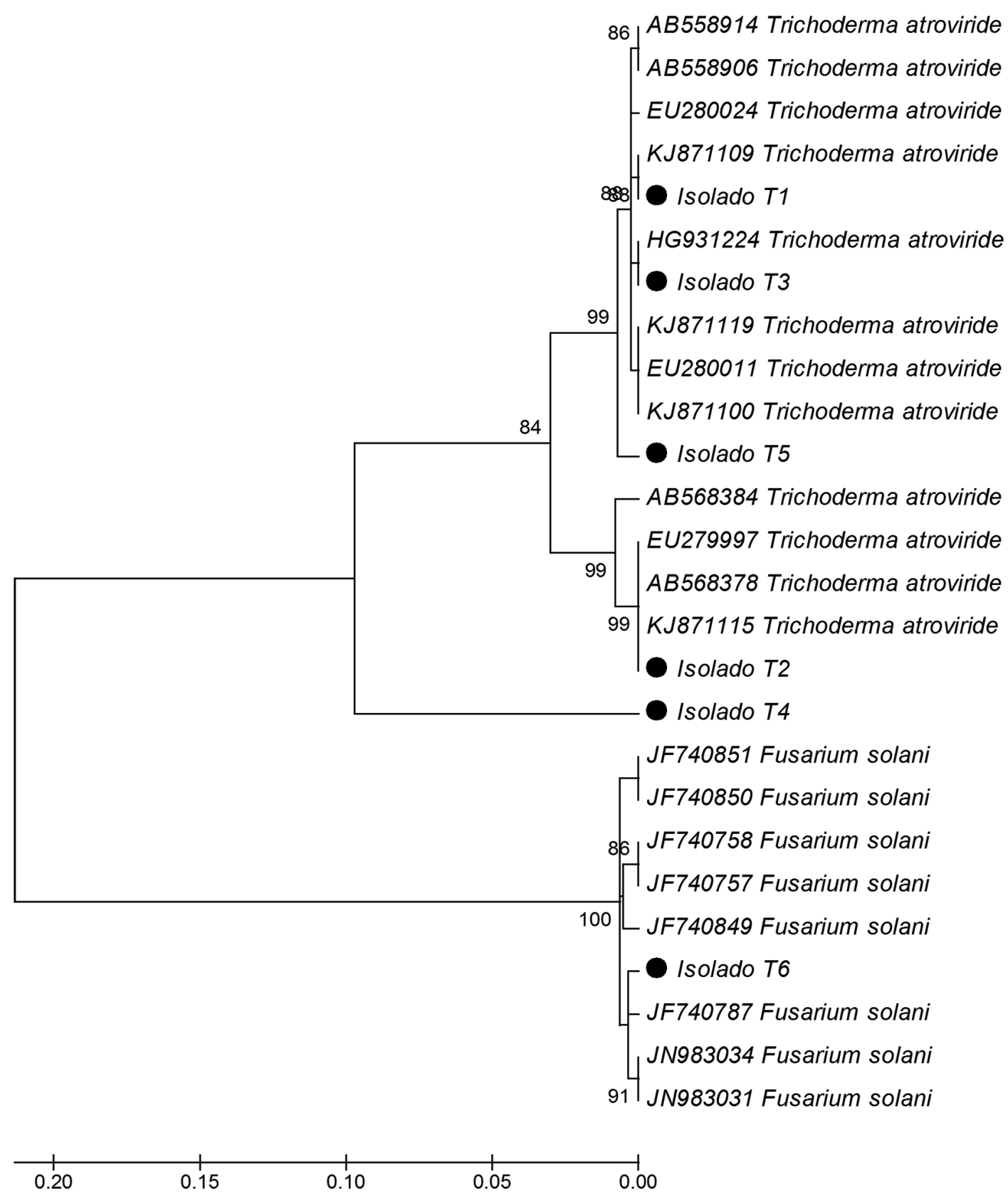

Figura 1. Dendrograma filogenético construído para os isolados $\mathrm{T}_{1}, \mathrm{~T}_{2}, \mathrm{~T}_{3}, \mathrm{~T}_{4}, \mathrm{~T}_{5}$ e $\mathrm{T}_{6}$, provenientes de madeira de Pinus spp. Figure 1. Phylogenetic dendrogram built to $\mathrm{T}_{1}, \mathrm{~T}_{2}, \mathrm{~T}_{3}, \mathrm{~T}_{4}, \mathrm{~T}_{5}$ e $\mathrm{T}_{6}$, isolated from Pinus spp. wood.

geralmente azuis a cinza-escuro (Silva et al., 2014), depreciando a madeira para a produção de móveis.

Henz \& Cardoso (2005) observaram o desenvolvimento de fungos em ripas de madeira de Pinus utilizadas na montagem de caixas para embalagem de hortaliças. Os fungos mais detectados foram Trichoderma harzianum e Rhizopus stolonifer. Hanada et al. (2003) realizaram um levantamento de fungos emboloradores e manchadores em madeira de 12 espécies florestais estocadas em 4 indústrias madeireiras de Manaus, AM, e obtiveram 106 isolados de fungos. Do gênero Trichoderma foram identificadas 4 espécies (T. harzianum, T. longibrachiatum, T. pseudokonigii e T. viride). As duas últimas espécies de Trichoderma citadas anteriormente pertencem ao complexo T. viride/atroviride/koningii (Lübeck et al., 
2004), do qual a espécie T. atroviride identificada no presente estudo também faz parte sendo, portanto, semelhante àquelas geneticamente.

Silva et al. (2014), ao testarem fungos isolados de cepas de madeira de eucaliptos deterioradas observaram pequenas perdas de massa provocadas com a inoculação de isolados de Trichoderma spp., quando comparados a outras espécies de fungos já reconhecidos como deterioradores de madeira. Segundo os autores, apesar de os fungos do gênero provocarem manchas externas (bolor) na madeira e serem os primeiros a colonizar o substrato, possuem pequena capacidade de deterioração da madeira.

São poucos os estudos já realizados em que o gênero Fusarium é associado à madeira. Hanada et al. (2003) encontraram duas espécies de Fusarium, sendo elas F. moniliforme e F. oxysporum associados à madeira de Hura creptans e Ceiba pentandra, respectivamente. Campos et al. (2013) isolaram F. oxysporum de madeira de cinco espécies florestais que apresentavam sintomas de ataque de fungos emboloradores. No presente estudo, o isolado $\mathrm{T}_{6}$ foi identificado como F. solani (Figura 1). Embora visualmente o fungo apresente sintoma de bolor, nem sempre é possível separar ou discernir com clareza se ele provoca bolor ou mancha na madeira sem um estudo histológico prévio (Hanada et al., 2003).

O presente estudo identificou a presença de fungos emboloradores das espécies F. solani e T. atroviride em madeira de Pinus spp. em Pelotas, Rio Grande do Sul. A partir da identificação específica desses agentes é possível o desenvolvimento de iniciativas na busca de formas e métodos de preservação da madeira, evitando-se o seu ataque.

\section{STATUS DA SUBMISSÃO}

Recebido: 29 abr., 2015

Aceito: 28 out., 2015

\section{AUTOR(ES) PARA CORRESPONDÊNCIA}

\section{Marilia Lazarotto}

Departamento de Horticultura e Silvicultura, Universidade Federal do Rio Grande do Sul UFRGS, Av. Bento Gonçalves, 7712, CEP 91540-000, Porto Alegre, RS, Brasil e-mail: marilia.lazarotto@ufrgs.br

\section{REFERÊNCIAS}

Campos RF. Efeito do óleo de copaíba no crescimento do fungo embolorador Fusarium oxysporum. In: Anais da LXV Reunião Anual da Sociedade Brasileira para o Progresso da Ciência; 2013; Recife. Recife: SBPC; 2013.

Hanada RE, Sales-Campos C, Abreu RLS, Pfenning L. Fungos emboloradores e manchadores de madeira em toras estocadas em indústrias madeireiras no município de Manaus, Amazonas, Brasil. Acta Amazonica 2003; 3(33): 483-488. http://dx.doi.org/10.1590/S004459672003000300013.

Henz GP, Cardoso FB. Absorção de água e proliferação de fungos em madeira de Pinus usada como embalagem para hortaliças. Horticultura Brasileira 2005; 23(1): 138-142. http://dx.doi.org/10.1590/S0102-05362005000100029.

Indústria Brasileira de Árvores - IBÁ. Relatório Ibá 2015. São Paulo; 2015. 64 p.

Kelley SS, Jellison J, Goodell B. Use of NIR and pyrolysisMBMS coupled with multivariate analysis for detecting the chemical changes associated with brown-rot biodegradation of spruce wood. FEMS Microbiology Letters 2002; 209(1): 107-111. http://dx.doi.org/10.1111/j.1574-6968.2002. tb11117.x. PMid:12007662.

Lübeck M, Bulat S, Alekhina I, Lieckfeldt E. Delineation of species within the Trichoderma viride/atroviride/ koningii complex by UP-PCR cross-blot hybridization. FEMS Microbiology Letters 2004; 237(2): 255-260. http:// dx.doi.org/10.1016/j.femsle.2004.06.041. PMid:15321670.

Machado DFM, Parzianello FR, Silva SCF, Antoniolli ZI. Trichoderma no Brasil: o fungo e o bioagente. Revista de Ciências Agrária 2012; 35(1): 274-288.

Rehner SA, Buckley EA. Beauveria phylogeny inferred from nuclear ITS and EF1-alpha sequences: evidence for cryptic diversification and links to Cordyceps teleomorphs. Mycologia 2005; 97(1): 84-98. http://dx.doi.org/10.3852/ mycologia.97.1.84. PMid:16389960.

Silva LF, Paes JB, Jesus WC Jr, Oliveira JTS, Furtado EL, Alves FR. Deterioração da madeira de Eucalyptus spp. por fungos xilófagos. Cerne 2014; 20(3): 393-400. http:// dx.doi.org/10.1590/01047760201420031462.

Zauza EAV, Alfenas AC, Mafia RG. Esterilização, preparo de meios de cultura e fatores associados ao cultivo de fitopatógenos. In: Alfenas AC, Mafia RG, editores. Métodos em fitopatologia. Viçosa: UFV; 2007. 